\title{
Correction to: European-Russian Space Cooperation
}

\author{
Brian Harvey
}

\section{Correction to:}

B. Harvey, European-Russian Space Cooperation, Springer Praxis Books, https://doi.org/10.1007/978-3-030-67686-5

The book was inadvertently published without updating the following corrections:
Abbreviations:
p. = page
1. = line
$\mathrm{fb}=$ from bottom

The updated versions of these chapters can be found at https://doi.org/10.1007/978-3-030-67686-5_1 https://doi.org/10.1007/978-3-030-67686-5_2 https://doi.org/10.1007/978-3-030-67686-5_3 https://doi.org/10.1007/978-3-030-67686-5_4 https://doi.org/10.1007/978-3-030-67686-5_5 https://doi.org/10.1007/978-3-030-67686-5 


\section{C2 Correction to: European-Russian Space Cooperation}

\section{Corrections:}

p.121: The photo of Rashid Sunyaev was replaced with this new photo:

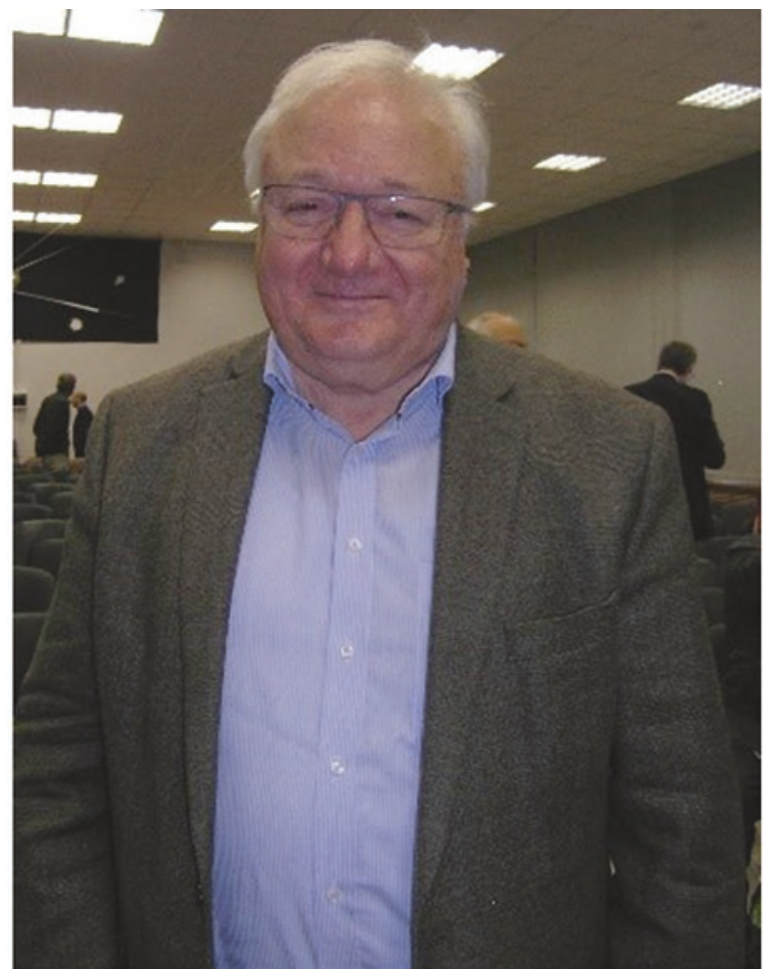

Rashid Sunyaev.

p.298, 1.8: "RD-0110" was replaced with "RD-0162".

p.298, 1.13, fb: The sentence "Methane-powered engines had long been a theme of Russian rocket engine development - a methane engine, the RD-301 had even been built..." was replaced with "Exotic-powered engines had long been a theme of Russian rocket engine development - a flourine ammonia engine, the RD-301 had even been built...".

p.299: The figure caption was replaced to read "RD-301 - the original exotic fuel engine".

p.3, 1.4: The phrase "the next day" was deleted, so the sentence reads "His delegation...".

p.57, 1. 10, fb: "M-2" was replaced with "M-3". 
p. 57, 1. 6, fb: "Bioxbox" was replaced with "Biobox".

p.58: The figure caption was replaced to read "Foton M-3. Marcel van Slogteren, ESA".

p.58, 1.1, fb: The text in bracket was deleted: "(outside experiments had not been possible in the shuttle)".

p.59: "Bion" was replaced with "Biopan" in figure caption.

p.63, 1.22: The word "agency" before "plane" was deleted.

p.69, 1.11, fb: The phrase "Orenburg in the Urals" was replaced with "Orenburg to the south-west of the Urals".

p.145, 1.7, fb: The text "M-1" was deleted from list, to read as "(Bion 9, 10)".

p.243, 1.4, fb: The word "built" was replaced with "overseen" so as to read "... were overseen by...".

p.244, 1.5 and 1.6: The sentence "Some adopted a dormant or dessicated state to survive" was deleted, but retaining reference "[45]".

p.263, 1.13: The word "Altas" has been replaced with "Atlas".

p.329, In Table 5.3, the word "impact" was replaced with "touchdown" in the last line of the table so as to read "intended touchdown".

p.333, 1.16: "2000” was replaced with "2020" so as to read "October 2020". 